\title{
The Effects of Foreign Cultures on the Women Clothes in the Tang Dynasty
}

\author{
Ding Ying \\ Jiangxi Institute of Fashion Technology,Department of Dress Design and Engineering \\ Jiangxi Institute of Fashion Technology, JF, Nanchang, Jiangxi \\ 185503378@qq.com
}

\section{Keywords: Tang Dynasty; Women clothes; Makeup; Foreign Culture; Hu’s Style}

\begin{abstract}
The clothes in every dynasties embody the factors of politic and culture in China, such as Tang dynasty. After the Benign Administration of Zhenguan Reign Period in Tang dynasty, the economic developed quickly. Due to the great territory, the decree unity and the material wealth, Tang dynasty had close intercourse with Tujue, Uighur, Tubo, Nanzhao, Japan, India and Persia. As one of the most open dynasties, Tang Dynasty was rich and opened to other countries in cultures. On one hand, its clothes kept the tradition of China; on the other hand, the clothes incorporated other styles from abroad. Both of them melted each other, and formed the clothe style of Tang dynasty with elegant grace and unique features. Especially the women clothes in Tang dynasty, with the high status of women, new aesthetic trend was appearing on the clothes style, hair style and makeup style. Under the melting of multi-culture in Tang dynasty, the paper analyzes the melting phenomenon between the Tang women clothes and abroad clothes. Today, the designers from all over the world create their designing through the absorbing from the traditional clothes.

The costumes belong to the culture phenomenon, which lays the politic factors under the background of different times. On one hand, the political environment affects the integral style of the clothes and its evolution process; on the other hand, the rulers also need rely on the clothes to foil the characteristics of political and its regime. The culture of Tang dynasty was rich and colorful, and had a long history. Regardless of politic, economic or culture, Tang dynasty was praised by the generations.

Founded in the $7^{\text {th }}$ century, when the rulers opened its soil and massive migration, at the same time, the Tang dynasty has been on its way to open. After the overthrow of the regime of the Sui dynasty by $\mathrm{Li}$ Yuan and his son Li Shimin, Tujue and the ancient cities of western region surrendered to Tang, which made Tang dynasty become a very powerful country. Due to the unity of the country, the stability of the politic, the economy was stable in Tang dynasty, and the price was very low, which benefited the prosperity of Tang dynasty. As a result, many foreign officials came to Tang dynasty, and the merchants were increasing by the attraction of Tang dynasty.

Without the convenient traffic, opening to the public would be difficulty. At that time, there were two roads which led to Tang dynasty, one was an overland by the merchants for the trade; the other was the sea lane for the convenience of shipping, which regularly commuted between the Indian Ocean and the sea. From that time, the westerners also began to understand the culture of Tang dynasty. During nearly three hundred years of Tang dynasty rule, the costumes of the Chinese nation had become an extremely important symbol in the history of Chinese costume after a long period of hereditary, evolution and development. The clothes in Tang dynasty did not only inherit the suit system of ancient representative clothes, but also accepted the foreign cultures and popularized them. At the same time, the interaction of Tang dynasty clothing with Asian countries apparel clothing had made great contribution to the development of communication for human being. Especially the women clothing in Tang dynasty, it reflected the open mind, the pioneering spirit, the distinct times and the strong national character in that time.

Tang dynasty, as the most prosperous time of feudal society, reached the summit in the ideas of the people and the production of the materials in the history. In Tang dynasty, the clothes were decorated through the flowers patterns and the style was open and fashion.
\end{abstract}


First, the political features are in Tang dynasty clothes. Since the ancient times, Chinese people paid attention to the form of the culture which mirrored the order of the society. The costumes was a tool of regulating the orders of different people and distinguishing the personal relationship by the rulers. The ritual, the instrument and the grade junior idea of inheritance wasn't dimmed, on the contrary, it showed more incisively and vividly.

Especially after the Anshi's Rebellion, the political situation in Tang dynasty was unstable, and the aesthetic culture was appearing sad, depressed and exquisite, which had become the main trend in Tang dynasty. With the change in art style in Tang dynasty, the clothes style had experienced the change from the fresh and bright in the beginning of Tang Dynasty; freedom and opening in prosperous Tang dynasty; colorful in Middle Tang and exquisite and delicate in late Tang dynasty. Therefore, in the different development period of Tang, the whole style of the clothes were appearing different characters.

In dealing with the foreign culture, the Tang dynasty's political strategy was absorbing more than rejection. The popularity of Hu's style and clothing fashion was a form of free and open political strategy in the Tang dynasty. The Hu's clothing mainly referred to the northern minorities and the Indian, Persian, Arabian, western ethnic costumes. According to the records in six code in Tang dynasty, the countries communicated with Tang dynasty had reached more than three hundred countries, at least there were more than seventy countries. The people who lived in Changan were the Han nation, in addition, there were Tubo, Japanese, Koreans, Persians, Arabs, etc., which made Changan be full of novelty and strange everywhere at that time. All kinds of languages, the distinctive costumes, folkway and folk-custom in photograph and the dizzying, the government not only didn't oppose the people to follow them, on the contrary, the government advocated them to imitated. During that time, the foreign culture were popular in Tang dynasty and melt with the glorious cultures in Tang dynasty. Eventually, they formed the colorful and graceful culture art trend.

Prosperity in the Tang dynasty costumes, showed the introduction and absorption without considering, the reform and the innovation of without considering. Its main features were the women clothing, integrating the traditional clothing, foreign apparel, as well as complete, the diversity of all kinds of hair style and decoration.

Second, pluralistic characteristic of women clothes in Tang dynasty. Before Tang dynasty, the women had always been deeply influenced by the feudal moral codes, the clothing were conservative and implicate. In the Tang dynasty, with the improvement of women status, the aesthetic view had great changes comparing with the past, the people in Tang dynasty were advocating fitness, fruitful posture, handsome women. Especially the women, if they were a little fat, they were beautiful. The women dress experienced great changes. The pursuit towards the beauty was brave and bold, it was a great surprise to the modern people.not mention to the ancient people (Figure 1. Women Clothes in Tang Dynasty).

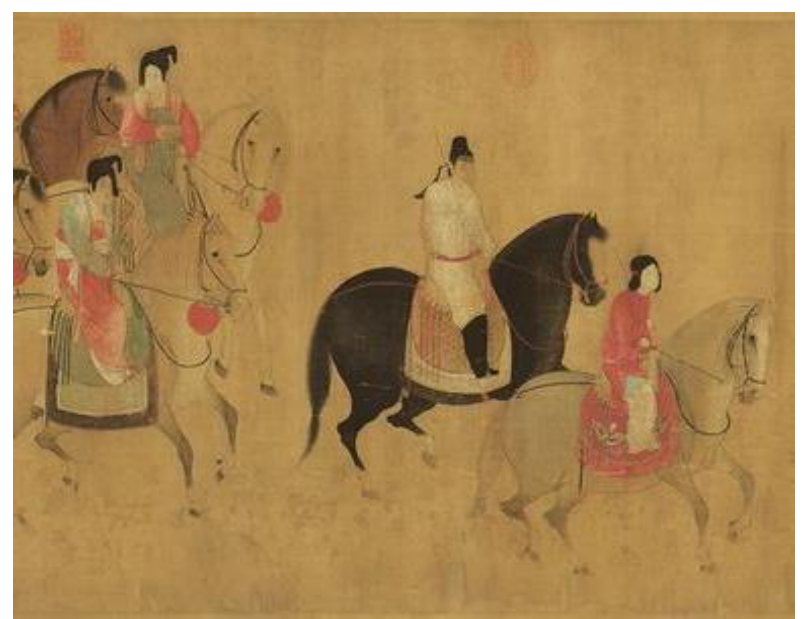

Figure 1. Women Clothes in Tang Dynasty 
The handicraft developed quickly in Tang dynasty, and the exchanges with the foreign countries were frequent. The traditional handicraft production technology were greatly improved and the strengthening of internal division mechanism were enforced than before. The official camp and private handicraft industry developed quick during this period. The significant development provided an important basis for the development of clothing. The pattern-dye, wax printing, printing printing technology were widely used, such as making silk decorative color in the Tang dynasty more colorful. Woven spinning process and the development of silk, printing and dyeing technology, provides a rich and colorful clothing material,. The color was more bright, more exquisite ornamentation.

Crown service system is the power symbol of feudal society level. As a feudal noble women, from the queen, the crown princess to the ordinary housing women, the dress what they worn were still retaining the traditional characteristics in China. The Queen usually worn three garments: Hui Bow clothing; Kodemari Rui and twinkle garment, which were typical clothes of the Han nationality dress. The crown princess and common women's dress also descended from the Han dynasty. The supporting mode and users of all kinds of dress had very big connection in different occasions. As early as the beginning of Tang dynasty, palace women began to wear popular collar of dress. Reaching the prosperous Tang, it were popular among the whole country. The women in Group Portrait Noblewomen showed their waist and chest, naked arm, shoulder and only wrap around gauze dress image, which was the most typical image in Tang dynasty big sleeve gauze unlined upper garment. The skirt styles varied in Tang dynasty, from the narrow of the beginning period of Tang dynasty to the loose hypertrophy of the prosperous Tang period, which were used to embody woman's grace, the beauty of the rich, well-developed (Fig. 2. Women Clothes in Tang Dynasty).

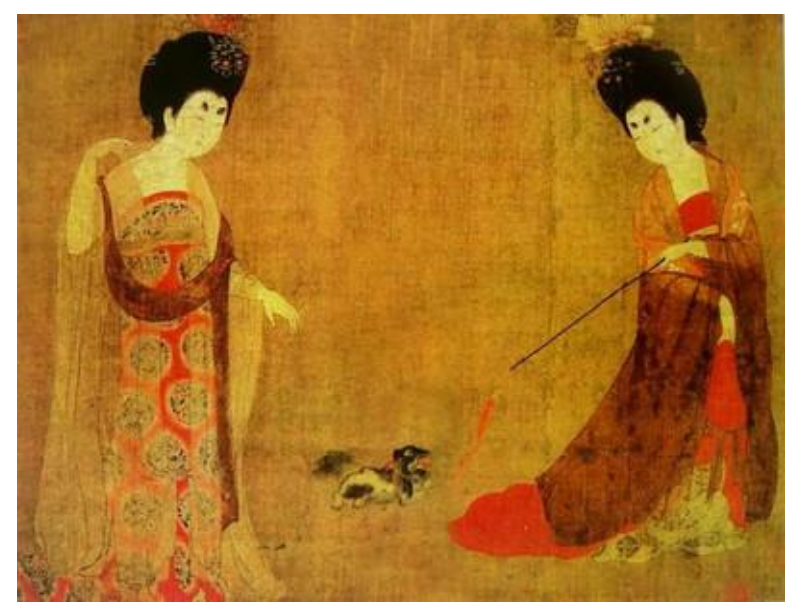

Figure 2. Women Clothes in Tang Dynasty

Tang dynasty is a dynasty which emphasized the fashion for all the time. Especially the women, they pursued the fashion than anybody. Politics, law, morality and etiquette couldn't restrain the pursuit to the beauty and the fashion. It is surprised to know that the court maid who were constrained greatly by the court moral codes were leading the fashion trend. As it is known, they had strong hierarchical ideology. They tried new styles for all the time and created new forms. The clothes which showed the chest and had low collars were produced under the pursuit of the court maid. In addition to the Palace, the palace aristocratic dress had been imitated by the folk woman. The skirt of the princess Anle was made of the feathers from more than one hundred birds. At the first sight, the skirt was one color, but if it is looked from the side, it had another color. That's to say its color changed according to the sun. What's more important, the form of the bird would jump into our sight. The skirt was famous works in the history of the embroidery. And it was imitated by many court maids. As a result, the lynch poultry animals in the mountains were hunted badly, nearly leave nothing, which fully showed the fashion at the time of that dynasty.Tang dynasty costumes are also very popular speed and update cycle, whenever Changan to launch a new ornaments, soon far away areas "to comb the jingshi sample". The popular speed and the round of 
the change of the clothes in Tang dynasty were fast. When there were new styles in the street of Changan, other areas would learn the example of the street in Changan.

At that time, the nomad clothes had great affects to the clothes in the Central Plains. Especially the popularity of the dance of Huxuan and the dance of Tuozhi made the Hu's clothes be popular in the Tang dynasty. The Huihe outfit and dance outfit were the main original clothes of the Tang women clothes. The Huihe was the minority of the northwest in Tang dynasty. The clothes of Huihe nationality was similar to today's clothing styles. Folding collar, wide jumpsuit, enough long to touch the earth, matching with the knot of the Huihe (Fig. 3. Women Clothes in Tang Dynasty). Besides the traditional styles of the dance clothes in Tang dynasty, other styles had the characters of the Western Regions. Of course, the clothes were matched with the spire's hat and cotton boots.

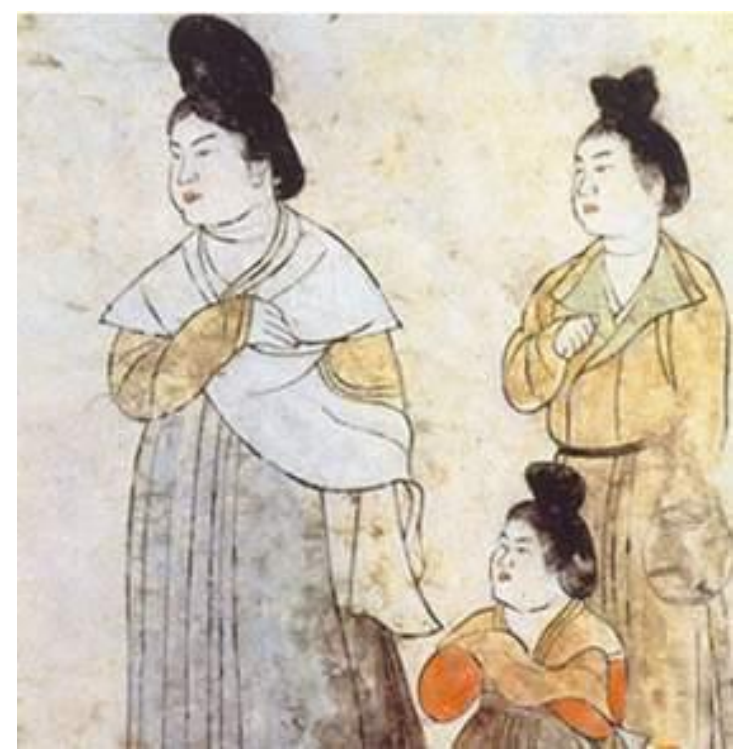

Figure 3. Women Clothes in Tang Dynasty

At the same time, the face adorning of the women in the Tang dynasty were complex and strange, even bizarre. In order to match the dress, the bun was tall and big. Sometimes, for the pursuit of the beauty, even the wig was joined. The face was decorated by all kinds of decoration, such as dimples, with rouge in transition on the face, which was used to beautify the face, especially in the Wei and Jin period, however, the Tang dynasty -- even more. In the late Tang dynasty, to deserve to go up in a low angle of eyebrow horoscopes paste painted lips. At the time of prosperous Tang dynasty, the poet of Bai Juyi called it crow makeup, seeming to give a person a kind of weeping, the feeling of melancholy. In the late Tang dynasty, the shape of the dimples was dot, the birds and beasts graphics were adding to the flowers. The place of the decoration were extending to the hole face from the original mouth and nose, and the type was strange and unique, which made people forget the whole five sense organs. It was very very strange and complex (Fig. 4. Female makeup in Tang dynasty). 


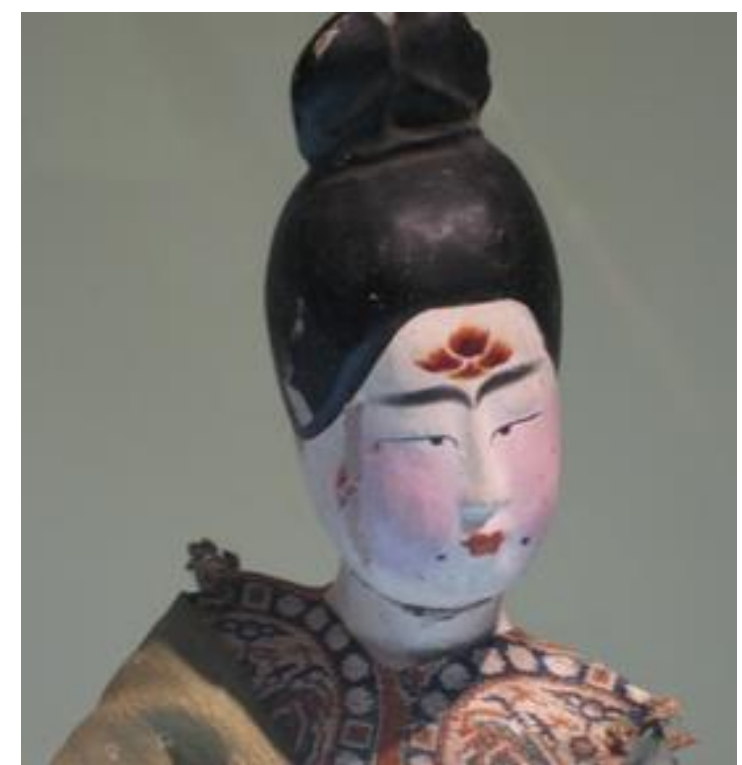

Figure 4. Female makeup in the Tang dynasty

Third, the foreign culture of affecting the women clothes in the Tang dynasty.The Tang dynasty were influenced by foreign cultures. Culture was the production of communication. In other words, the cultures were developing in the communication, If there were no communication, there were no progress of the cultural development. Just through various means of communication, which made the regional culture, national culture improve together to form a new culture through the melting of each other. The Tang dynasty had interactions with the East Asia, Southeast Asia and Middle East countries. The affects from literature and art to life styles and customs can be felt. Due to a large number of foreign immigration to check in, the spread of business contacts, the spread of the religion, their habits, culture and customs of the nations, affected Changan, Luoyang, Yangzhou city in a wide range, as well as the important city like Guangzhou. The Chinese and foreign culture communion caused the prosperous of the Tang dynasty, especially in the culture and politic, they all developed very quickly in the Tang dynasty and had a great significance towards the following dynasties.

As it is known, towards absorbing the foreign cultures, the Tang dynasty took the attitude that swallowed everything and anything uncritically, which made the clothes in Tang dynasty be full of national feeling and opening ideology, especially in the women clothes. Beside the official clothes with politic color in Tang dynasty, the daily women clothes expressed the ideology: bold and open; pursuit the beauty feeling; revealing the spirit of the times. In the ideology and culture, the Tang dynasty inherited from the Wei and Jin, southern and northern dynasties, containing the foreign cultures. In Tang dynasty, due to Political enlightenment, economic prosperity, social stability, the frequent exchange between Chinese and foreign countries, leading the Tang dynasty into the social background of accommodating different ideology and culture forms. Compared to the Han dynasty, the Tang dynasty was generous, elegant and grandeur, which provided useful conditions for the development of the women clothes. Just because of that, the women clothes in Tang dynasty were magnificent and colorful. Due to the background of the opening, the choosing of women clothes was free. Especially the strange psychology of the women in that time, they did not only wear Hu's clothes, but also wore men clothes. It was said that Taiping Princess began the example of women wearing of men clothing. When Tang Gaozong was meeting the guests, she worn the men clothes in public. the foreign people accepted the wearing method greatly after the news was sent to the folk, and a new trend was forming gradually.

The territory in the Tang dynasty was vast. The dynasty had close interaction with Tujue in northwest, Uighur, Tubo in southwest, Nanzhao and many minority nations in Bohai in northeast. As you know, Changan was one of the most development cities in the world. By the way of Xinjiang, Changan would get to India, Persia, Mediterranean sea, and the road was very busy. When it comes to the sea road, through the port in Guangzhou, it could get to west India sea 
through South sea, the wears in Africa and countries in south Mediterranean sea. There were no doubt the interaction between the west and Korea. The Tang dynasty took the open police towards foreign culture. Due to its national confidence and cohesion, after the absorbing of foreign culture, they had become the supplement and nourishment of the culture in the Tang dynasty. That's why the dynasty was generous and grandeur.

It is often said that Greatness in Trivialness, which is suitable to the clothes in the Tang dynasty. Just because of the prosperity in clothes, we saw the prosperity of the country. The dynasty was unity for a long time, the social was stable from the politic environment, the productivity made great progress, the handcraft was perfect, the feudal economic appeared prosperous. Especially the frequent exchange and absorbing of foreign culture, which all paid a base for the development of the politic and the culture in Tang dynasty. Just because of the development of the society, the development of the clothes had become a milestone in history.

On the whole, the cultures from other countries made the culture in the Tang dynasty become colorful and opening, which had a great significance towards the later dynasties.

\section{References}

[1] Huang Nengfu, Qiao Qiaoling the world of the clothes, the Chinese Publishing House,2009

[2] Hua Mei, the History of the Chinese Clothes,Tianjin people's fine arts publishing house, 1994 ,the second version

[3] Yuan Ze,the History of the Chinese Clothes, China's textile press, Oct, 2005

[4] ]Xie Fu(American), Wu Yugui, the Foreign Civilization of the Tang Dynasty, the Press of Shanxi Normal University,2005

[5] Shen Congwen, the Research of the Chinese Ancient Costumes from Shen Congwen, The commercial press, 2001

[6] Huang Nengfu, Chen Juanjuan, the History of the Chinese Clothes, Shanghai's people press, 2014

[7] Xu Jing, the History of the Chinese Clothes, Donghua University Press, 2010

[8] Huang Shilong, A Simple Introduction to the History of the Chinese Clothes, Shanghai culture press. 2007

[9] ]Zhu Gekai, the Experience of the Clothes Culture in China--the Rebirth of the Civilization, China Textile Press,2007

[10]Jia Xizeng, the Art History of the Chinese Clothes,Tianjin people's fine arts publishing house, 2009

[11]Hua Mei, the History of the Chinese Clothes, China Textile Press,2007

[12]Zhang Jingqiong, Cao Ze, the History of the Chinese Clothes that We could See,the Chinese Publishing House, 2012 